\title{
Optimization of the Control Scope of the Technical Means of the Vessel during Assessment of its Readiness for Sailing in Ice Conditions
}

\author{
Anisimov A.N., Razvozov S.Yu., Menshikov V.I.
}

\begin{abstract}
The task of optimizing the procedure for monitoring the technical means of a vessel preparing to sail in ice conditions is being considered, and the control procedure model is being drawn up for a system that includes a certain final number of technical means, that should be operational throughout the upcoming voyage, ensuring the safe operation of the vessel. It is proposed to search for a variety of vessel's technical means, the verification of which maximizes the probability of trouble-free operation of the vessel as a whole by the time of the end of the control operation, with the limitation from above for the time of control. In addition, it is shown that it is possible to obtain a sequence of elementary checks, which will meet the condition of the maximum probability of failure of the system of technical means at the time of its shutdown. A targeted function that can be found by dynamic programming in the form of a n-step process and further.
\end{abstract}

Keywords : vessel, optimization of technical control, state of readiness for swimming, ice conditions.

\section{INTRODUCTION}

Control over the vessel's readiness for sailing in ice conditions in the optimal volume allows increasing the safety of sailing due to the effective identification and subsequent replacement of technical means capable of failures [1], [2]. On the other hand, the control is accompanied by negative impacts on technical means due to the inclusion of these means and the appearance of failures in the control process. Obviously, such a control scope and such a time spent on technical means in the on state, at which the control effectiveness of assessing the readiness of vessel for sailing in ice conditions is maximum for a vessel considered as a combination of technical means [3], [4]. Therefore, it is further advisable to consider the problem of optimizing the control scope of ship's technical means taking into account their failures arising from those natural features that arise in a vessel when sailing in the Arctic zone for those cases when the time for conducting control operations is limited from above [5].

Revised Manuscript Received on October 15, 2019.

* Correspondence Author

Anisimov A.N., Admiral Makarov State University of Maritime and Inland Shipping, 198035, Russia, Saint-Petersburg, Dvin-skaya st., 5/7.

Razvozov S.Yu., Admiral Makarov State University of Maritime and Inland Shipping, 198035, Russia, Saint-Petersburg, Dvin-skaya st., 5/7.

Menshikov V.I., Admiral Makarov State University of Maritime and Inland Shipping, 198035, Russia, Saint-Petersburg, Dvin-skaya st., 5/7.

\section{PROBLEM STATEMENT}

Consider the vessel as a system that includes $\mathrm{n}$ technical means that shall function during the forthcoming ice sailing, ensuring the safe operation of this vessel. To carry out control of the vessel, the inclusion of technical means is necessary in order to be sure that all technical means are in working condition [6].

Let every technical means $\mathrm{i}(\mathrm{i}=1,2, \ldots \mathrm{n})$ be characterized by the probability of no-failure operation pi by the time of control, time spent on its verification ti and failure rate in operating mode $\lambda \mathrm{i}=$ const. If the control inspection fails, the item $i$ is replaced by a known good one. Therefore, we will further assume that the probability of no-failure operation of a technical means is equal to one at the time of its inspection. It is required to find a lot of vessel technical means, whose inspection maximizes the probability of vessel's no-failure operation as a whole in ice conditions by the end of control operation, with restriction on the control time from above T0. Moreover, let us determine the probability of no-failure operation of vessel technical means at the time of their shutdown in the conditions when a lot of $\mathrm{S}(\mathrm{S} \cdot \mathrm{N}=\{1,2, \ldots, \mathrm{n}\})$ vessel technical means are controlled and the time spent on the system of vessel technical means in the on state is $\mathrm{T}$, while $\mathrm{T} \leq \mathrm{T} 0$.

If the technical means $i(i \neq S)$ are not inspected, their probability of no-failure operation by the time the system of technical means is turned off will be piri,(T), ri $(\mathrm{T})=\exp$ $\lambda \mathrm{tT}$ and if the technical means $\mathrm{i}(\mathrm{i} \cdot \mathrm{S})$ are inspected and inspection ends at the time $\tau \mathrm{i}(0<\tau \mathrm{i} \leq \mathrm{T})$, then the probability considered for an item $\mathrm{i}$ will be $\mathrm{ri},(\mathrm{T}-\tau \mathrm{i})=\exp -\lambda \mathrm{i}(\mathrm{T}-\tau \mathrm{i})$. Then the probability of no-failure operation of the system of technical means $\mathrm{D}(\mathrm{S})$ at the time of its shutdown can be determined in the following form:

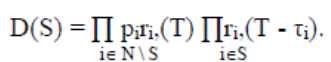

At the same time, the total time spent on inspection $\mathrm{S}$ of the technical means will be

$$
\mathrm{T}(\mathrm{S})=\sum_{\mathrm{i} \in \mathrm{S}} \mathrm{t}_{\mathrm{i}} \leq \mathrm{T}
$$


It can be seen from the expression (1) that the value $D(S)$ depends on $\tau$ i values, which, in turn, are determined by the sequence of inspections of $S$ elements. $D(S)$ maximum complies with inspections conducted in the sequence under which the following condition is met

$$
\lambda_{\mathrm{i}} / \mathrm{t}_{\mathrm{i}}<\lambda_{\mathrm{i}+1} / \mathrm{t}_{\mathrm{i}+1}, \mathrm{i} \in \mathrm{S} \text {. }
$$

To prove the validity of condition (2), we select two adjacent inspections in the sequence of inspections $S$ of technical means, for example, $\alpha$ and $\beta$. Using $\mathrm{D}(\alpha, \beta, \mathrm{S})$ and $\mathrm{D}(\beta, \alpha, \mathrm{S})$ let us determine the probabilities of no-failure operation of the system of technical means at the time of its shutdown during inspections of these means $\alpha$ and $\beta$, respectively, in the sequence $\alpha, \beta$ and $\beta, \alpha$. Then, using expression (1), we find the following relation

$$
\mathrm{D}(\alpha, \beta, \mathrm{S}) / \mathrm{D}(\beta, \alpha, \mathrm{S})=\exp -\lambda_{\alpha} t_{\beta}+\lambda_{\beta} t_{\alpha}
$$

It follows from the expression (3) that $\mathrm{D}(\alpha, \beta, \mathrm{S})>\mathrm{D}(\beta, \alpha$, $S)$, i.e. conducting inspections of technical means in the sequence $\alpha \beta$ gives a greater effect, if the following condition is met

$$
-\lambda_{\alpha} t_{\beta}+\lambda_{\beta} t_{\alpha}>0
$$

Or

$$
\lambda_{\alpha} / \mathrm{t}_{\alpha}<\lambda_{\beta} / \mathrm{t}_{\beta}
$$

If inspections of all technical means included in the range $\mathrm{S}$ are considered in pairs in a similar way, then we can get a sequence of inspections that will meet the condition (2). Therefore, taking into account expression (2), we obtain

$$
\begin{aligned}
& \tau_{\mathrm{i}}=\mathrm{T}-\sum_{\gamma \in \mathrm{S}} \mathrm{t}_{\gamma} \\
& \gamma>\mathrm{i}
\end{aligned}
$$

At the same time, it follows from the expression (1) that the value $D(S)$ is maximum at $T=T(S)$. In this case

$$
\begin{array}{r}
\tau_{\mathrm{i}}=\tau_{\mathrm{i}}(\mathrm{S})=\mathrm{T}(\mathrm{S})-\sum_{\substack{\gamma \in \mathrm{S} \\
\gamma>\mathrm{i}}} \mathrm{t}_{\gamma} \\
\end{array}
$$

Thus, the problem formulated relates to finding the range $\mathrm{S}^{*}$, which corresponds to the maximum value of the probability of no-failure operation of the system of technical means (vessel) by the time they are turned off

$$
\mathrm{D}^{*}\left(\mathrm{~S}^{*}\right)=\max _{\mathrm{S}} \prod_{\mathrm{i} \in \mathrm{N} \backslash \mathrm{S}} \mathrm{p}_{\mathrm{i}} \mathrm{r}_{\mathrm{i}},(\mathrm{T}(\mathrm{S})) \prod_{\mathrm{i} \in \mathrm{S}} \mathrm{r}_{\mathrm{i}},\left(\mathrm{T}(\mathrm{S})-\tau_{\mathrm{i}}(\mathrm{S})\right) .
$$

subject to inequality (2) and the requirement $\mathrm{T}(\mathrm{S}) \leq \mathrm{T} 0$. The objective function (4) can be used in the preparation of mathematic model of the procedure for optimal control of vessel readiness for sailing in ice conditions [7].

\section{METHODOLOGY FOR THE FORMATION OF OPTIMAL CONTROL PROCEDURE OF THE STATE OF READINESS}

To compile a mathematical model of the optimal control procedure of the vessel's readiness for sailing in ice conditions, we introduce binary variables $\mathrm{x}_{\mathrm{i}}(\mathrm{i}=1$, $2, \ldots, n)$, taking the values of $x_{i}=1$, if the technical means $i$ are inspected $(i \in S)$, and $x_{i}=0$ otherwise $(\mathrm{i} \notin \mathrm{S})$. Then the objective function of the optimal control operation (4) after simple transformations can be written in the following alternative form. Find the set $X^{*}=\{$ $\left.\mathrm{x}^{*}, \mathrm{i}=1, \mathrm{n}\right\}$, with which we can get

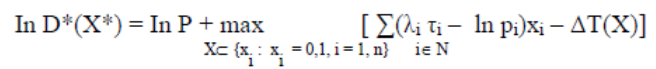

$$
\begin{aligned}
& \mathrm{T}(\mathrm{X})=\sum_{\mathrm{i} \in \mathrm{N}} \mathrm{t}_{\mathrm{i}} \mathrm{x}_{\mathrm{i}} \leq \mathrm{T}^{0},
\end{aligned}
$$

Where

$$
\begin{aligned}
& \mathrm{P}=\prod_{\mathrm{i} \in \mathrm{N}} \mathrm{p}_{\mathrm{i}}, \quad \tau_{\mathrm{i}}=\tau_{\mathrm{i}}(\mathrm{X})=\mathrm{T}(\mathrm{X})-\sum_{\mathrm{i} \in \mathrm{N}} \mathrm{t}_{\gamma} \mathrm{x}_{\gamma}, \quad \Lambda=\sum_{\mathrm{i} \in \mathrm{N}} \lambda_{\mathrm{i}} . \\
& \gamma \geq \mathrm{i}
\end{aligned}
$$

To compile a mathematical model of the control operation within the framework of the objective function (5), we fix a certain value of the time spent by the system of technical means in the on state $\mathrm{T}\left(0<\mathrm{T}<\mathrm{T}^{0}\right)$. While $\Lambda[\mathrm{T}(\mathrm{X})=\mathrm{T}]$ $=$ const. As a result, we obtain a particular task of finding an admissible value [8]

$$
\begin{aligned}
& \operatorname{In} \mathrm{D}^{0}(\mathrm{~T}) \underset{\mathrm{X} \subset\left\{\mathrm{x}_{\mathrm{i}}: \mathrm{x}, \mathrm{In}=0,1, \mathrm{i}=1, \mathrm{n}\right\}}{\operatorname{In}} \quad \sum\left(\lambda_{\mathrm{i}} \mathrm{T}_{\mathrm{i}}-\ln \mathrm{p}_{\mathrm{i}}\right) \mathrm{x}_{\mathrm{i}} \\
& i \in \mathbb{N} \\
& \sum_{i \in N} t_{i} x_{i} \leq T \\
& \tau_{i}=T-\sum_{i \in N} t_{\gamma} x_{\gamma}, \\
& \gamma \geq \mathrm{i}
\end{aligned}
$$

Let us single out the following function in the expression (6):

$$
\mathrm{F}(\mathrm{T})=\max _{X i \in N} \sum\left(\lambda_{\mathrm{i}} \tau_{\mathrm{i}}-\ln _{i \in N} \mathrm{p}_{\mathrm{i}}\right) \mathrm{x}_{\mathrm{i}} \quad \sum \mathrm{t}_{\gamma} \mathrm{x}_{\gamma} \leq \mathrm{T} .
$$

If $\mathrm{F}(\mathrm{B})$ is determined for all values $\mathrm{T}\left(0 \leq \mathrm{T} \leq \mathrm{T}^{0}\right)$, then the desired range $\mathrm{D}^{*}$ and the corresponding set $\mathrm{X}^{*}$ can be obtained from the expression:

$$
\text { In } D^{*}=\max \operatorname{In} D^{0}(T)=\operatorname{In} P+\max [F(T)-\Lambda T] .
$$

The function $\mathrm{F}(\mathrm{B})$ can be found using dynamic programming as an n-step process [9]. To derive a recurrence relation on the $\mathrm{i}-\mathrm{th}$ step, let us suppose that the following function is determined on $n-1$ step

$$
\begin{aligned}
\mathrm{F}_{\mathrm{n}-1}\left(\mathrm{~T}_{\mathrm{n}-1}\right)=\max _{\mathrm{X}_{\mathrm{n}-1}} & \sum\left(\lambda_{\mathrm{i}} \tau_{\mathrm{i}}-\ln \mathrm{p}_{\mathrm{i}}\right) \mathrm{x}_{\mathrm{i}} \\
& \\
\sum_{\mathrm{i} \in \mathrm{N} \backslash \mathrm{N} \backslash \mathrm{n}} \mathrm{x}_{\gamma}, \leq \mathrm{T}_{\mathrm{n}-1}, & 0 \leq \mathrm{T}_{\mathrm{n}-1} \leq \mathrm{T}^{0}, \mathrm{X}_{\mathrm{n}-1} \subset\left\{\mathrm{x}_{\mathrm{i}}: \mathrm{x}_{\mathrm{i}}=0,1, \mathrm{i}=1, \mathrm{n}-1\right\} .
\end{aligned}
$$

Since $\tau_{\mathrm{n}}=\mathrm{T}$, , taking account the expression (2), then we can write the following for $\mathrm{F}(\mathrm{B})$ : 


$$
\begin{gathered}
F(B)=\max _{x_{n}}\left[\left(\lambda_{n} T--\ln p_{n}\right) x_{n}+F_{n-1}\left(T-t_{n} x_{n}\right)\right], \\
t_{n} x_{n} \leq T, 0 \leq T \leq T^{0} .
\end{gathered}
$$

In turn, let us determine $\mathrm{F}_{\mathrm{n}-1}\left(\mathrm{~T}_{\mathrm{n}-1}\right)$ in the form of [10]

$$
\begin{gathered}
F_{n-1}\left(T_{i-1}\right)=\underset{\substack{x_{n-1} \\
\max }}{\left[\left(\lambda_{n-1} T_{n-1}-\ln p_{n-1}\right) x_{n-1}+F_{n-2}\left(T_{n-1}-t_{n-1} x_{n-1}\right]\right.} \\
t_{n-1} x_{n-1} \leq T_{n-1}, \quad 0 \leq T_{n-1} \leq T^{0},
\end{gathered}
$$

Where,

$$
\begin{aligned}
& \mathrm{F}_{\mathrm{n}-2}\left(\mathrm{~T}_{\mathrm{i}-2}\right)=\max \quad \sum\left(\lambda_{\mathrm{i}} \tau_{\mathrm{i}}-\ln \mathrm{p}_{\mathrm{i}}\right) \mathrm{x}_{\mathrm{i}} \\
& \mathrm{x}_{\mathrm{n}-2} \quad \mathrm{i} \in \mathrm{N} \backslash \mathrm{n}, \mathrm{n}-1 \\
& \sum \mathrm{t}_{\mathrm{\gamma}} \mathrm{x}_{\gamma}, \leq \mathrm{T}_{\mathrm{n}-2}, \quad 0 \leq \mathrm{T}_{\mathrm{n}-2} \leq \mathrm{T}^{0}, \mathrm{X}_{\mathrm{n}-2} \subset\left\{\mathrm{x}_{\mathrm{i}}: \mathrm{x}_{\mathrm{i}}=0,1, \mathrm{i}=1, \mathrm{n}-2\right\} .
\end{aligned}
$$

Continuing in a similar way, we receive in the $\mathrm{i}-\mathrm{th}$ step,

$F_{i}\left(T_{i}\right)=\max \left[\left(\lambda_{i} T_{i}-\ln p_{i}\right) x_{i}+F_{i-1}\left(T-t_{i} x_{i}\right)\right]$,

As a result of sequential calculation (8) in step n, we find $\mathrm{F}_{\mathrm{n}}\left(\mathrm{B}_{\mathrm{n}}\right)=\mathrm{F}(\mathrm{T})$.

\section{DISCUSSION OF THE PROCESS OF OBTAINING CONTROL PROCEDURE}

Let us illustrate the application of the proposed mathematical model for the procedure formation of optimizing control scope of a vessel's technical means when assessing the state of readiness for sailing in ice conditions using a simple example. Let the scope of vessel inspections include the technical means $n=4$. Source data for each $\mathrm{i}$ technical means are presented in Table 1 , and the technical means in the table are ordered in accordance with the condition (2).

Table 1

\begin{tabular}{|c|c|c|c|c|}
\hline $\mathrm{i}$ & $\mathrm{t}_{\mathrm{i}}$ hour & $\begin{array}{c}\lambda_{\mathrm{i}} 1 / \\
\text { hour }\end{array}$ & $\mathrm{p}_{\mathrm{i}}$ & $\lambda_{\mathrm{i}} / \mathrm{t}_{\mathrm{i}}$ \\
\hline 1 & 4 & $\begin{array}{c}1.3 \times 10 \\
-2\end{array}$ & 0.97 & 3.25 \\
\hline 2 & 1 & $6 \times 10^{-3}$ & 0.9 & 6 \\
\hline
\end{tabular}

To conduct a control operation to determine the readiness foe sailing in ice conditions, a control time is set as $\mathrm{T}^{0}=6$ hours. Then referring to equation (8), let us calculate $F_{i}\left(T_{i}\right), i=1,2,3,4$ (Table 2). Table 2 includes relevant sets for each value $T_{i}-X_{i}\left(T_{i}\right)=\left\{x_{1}, x_{2}, \ldots, x_{i}, T_{i}\right\}$. The result of solving expression (8) is a function $\mathrm{F}_{4}\left(\mathrm{~T}_{4}\right)$.

Table 2

\begin{tabular}{|c|c|c|c|c|c|}
\hline $\mathrm{F}_{1}\left(\mathrm{~T}_{1}\right), \mathrm{T}_{1}, \mathrm{x}_{1}$ & $0,0,0$ & $0,082,4,1$ & - & - & - \\
\hline $\mathrm{F}_{2}\left(\mathrm{~T}_{2}\right), \mathrm{T}_{2}, \mathrm{x}_{1}, \mathrm{x}_{2}$ & $0,0,0,0$ & $0,111,1,0,1$ & $0,218,5,1,1$ & - & - \\
\hline $\begin{array}{c}\mathrm{F}_{3}\left(\mathrm{~T}_{3}\right), \mathrm{T}_{3}, \mathrm{x}_{1}, \\
\mathrm{x}_{2}, \mathrm{x}_{3}\end{array}$ & $0,0,0,0,0$ & $0,111,1,0,1,0$ & $0,252,4,0,1,1$ & - & - \\
\hline $\begin{array}{c}\mathrm{F}_{4}\left(\mathrm{~T}_{4}\right), \mathrm{T}_{4}, \mathrm{x}_{1}, \\
\mathrm{x}_{2}, \mathrm{x}_{3}, \mathrm{x}_{4}\end{array}$ & $0,0,0,0,0,0$ & $0,111,1,0,1,0$, & $0,183,2,0.0,0$, & $0,345,3,0,1,0$, & $0,635,6,0,1,1$, \\
\hline $\mathrm{D}^{0}(\mathrm{~T})$ & 0.787 & 0.797 & 0.776 & 0.826 & 0.820 \\
\hline
\end{tabular}

The bottom line of Table 2 shows the results of calculations using the expression (7) of values $\mathrm{D}^{0}$ for each $\mathrm{T}=\mathrm{T}_{4}$. As follows from Table 2 , maximum value $\mathrm{D}^{*}=$ 0.826 takes place at $\mathrm{T}=3$ hours. Moreover, we have a set $\mathrm{X}^{*}$ $=\{0,1,0,1\}$, that is, the optimal control scope includes inspections of technical means 2 and 4 .

\section{CONCLUSION}

We formulated the task to optimize the control procedure of the technical means of the vessel preparing to sail in ice conditions, when the procedure model is drawn up for such a system, which, including some finite number of technical means, will function in such a way throughout the ice sailing, to ensure safe vessel operation in the polar latitudes of the Arctic.

We allocated a variety of vessel technical means, whose inspection in ice conditions, when limited from above for the time of control, is able to maximize the likelihood of a vessel's no-failure operation in general. In addition, the work showed that it is possible to draw up such a sequence of elementary inspections of vessel technical means that meets

the condition for the maximum probability of vessel's no-failure operation when sailing in the polar latitudes of the Arctic.

The objective function found by the dynamic programming method and presented as an n-step process can be used in the preparation of a mathematical model for optimal control of the vessel's readiness for sailing in ice conditions. In addition, within the framework of this objective function, we proposed a design scheme to determine the number and order of control of vessel technical means, subject to the maximum probability of the vessel's readiness for ice sailing.

\section{REFERENCES}

1. Guidance on the application of the provisions of the International Code for Vessels Operated in Polar Waters (Polar Code). ND. No. 2 - 030101 031. Russian Maritime Register of Shipping. St. Petersburg. 2017. 26 p.

2. Verzakov G. F., Kinsht V.N., Rabinovich V.I., Timonen L.S. Introduction to technical diagnostics. Energiya, 1968.

3. Novotarsky V.A., Staroselets V.G. About an algorithm for optimizing the synthesis of complex systems. Automation and Telemechanics, No. 1, pp. 144-154, 1972. 

Sailing in Ice Conditions

4. Petrov V.I. The majority-gradient method for solving the problem of optimizing the sequential performance control procedure. ATI No. 2, 1970, P. $129-136$.

5. Buslenko, N.P. Modeling of complex systems / N.P. Buslenko. - M.: Nauka, 1978. - 400 p.

6. Collection of operational standards for the planning of transport fleet. Samara: Volgotanker, 1994. - 367 p.

7. Organization of management processes. Under the total ed. Made by G. Kh. Popova. M., Ekonomika, 1975.

8. Apatin, E.F. To the issue of formulation and solution of multicriteria transport type problems / E.F. Apatin, V.K. Kalachev. // Problems of river transport: collection of scientific articles. / GIIVT. - Gorky, 1980. - P. 61-62.

9. Bellman R., Dreyfus S. Applied problems of dynamic programming, M.: "Nauka". 1965.

10. Ivanov, V.M. The solution of the problem of optimal use of the fleet with a limitation on gross productivity / V.M. Ivanov, V.I. Kozhukhar // Articles / GIIVT. - Gorky, 1982. - Issue 190. - P. 28-35. 